\title{
A UNIÃO ENTRE PESSOAS DO MESMO SEXO NA JURISPRUDÊNCIA DO TRIBUNAL EUROPEU DE DIREITOS HUMANOS (ECTHR): OLIARI V. ITALY
}

\author{
Raphael Rego Borges Ribeiro*
}

\section{Resumo:}

Neste artigo, estudou-se o caso Oliari v. Italy, no qual se discutiu o reconhecimento de casais formados por pessoas do mesmo sexo como entidades familiares. Usou-se o método historiográfico com consulta a fontes primárias. Observou-se que a ECtHR compreendeu que a falta de proteção como família prejudicava esses casais, pois lhes privava de diversos direitos e deveres. A ECtHR decidiu que a Itália tinha violado o direito à vida privada e familiar dos requerentes, tendo assim o dever de legislar sobre a matéria. Contudo, a ECtHR entendeu que esse reconhecimento jurídico não necessariamente significava um direito ao casamento homossexual.

\section{Palavras-chave:}

União entre pessoas do mesmo sexo; União civil; Casamento

\section{SAME-SEX UNIONS IN THE EUROPEAN COURT OF HUMAN RIGHTS (ECTHR): OLIARI V. ITALY}

\begin{abstract}
:
In this paper, I studied Oliari v. Italy, a case in which the legal recognition of same-sex couples was discussed. I used the historiographic method, delving into primary sources. I saw that ECtHR understood that the lack of legal protection as families harmed those couples because it deprived them of various rights and duties. ECtHR decided that Italy had violated the applicants' right to private and family life, thus it had a positive obligation of regulating the issue. However, ECtHR understood that that legal recognition did not necessarily mean a right to same-sex marriage.
\end{abstract}

Keywords:

Same-sex relationships; civil partnership; marriage

\section{INTRODUÇÃO}

Neste artigo, será observado Oliari and Others v. Italy, um caso paradigmático julgado pela European Court of Human Rights (ECtHR), no qual a Corte, à luz da Convenção Europeia dos Direitos do Homem e das Liberdades Fundamentais (CEDH), debruçou-se sobre o direito de casais formados por duas pessoas do mesmo sexo terem as suas uniões formalmente reconhecidas enquanto entidades familiares. Muitas vezes, os debates mais profundos acerca da proteção aos direitos fundamentais acabam competindo aos tribunais

\footnotetext{
* Bacharel, Mestre e Doutor em Direito pela Universidade Federal da Bahia. Pesquisou no Health Law Centre da University of Ottawa (Canadá). Professor de Direito Civil na Universidade Federal do Oeste da Bahia.
} 
constitucionais ou às cortes internacionais de Direitos Humanos, entre outros motivos em razão da inércia legislativa ou da ação discriminatória das maiorias parlamentares em detrimento dos direitos das minorias. Isso é verdade para o Brasil e também para os países europeus, incluindo a Itália.

A presente pesquisa se justifica em razão da sua contribuição para a divulgação à comunidade jurídica brasileira da jurisprudência europeia em matéria de direitos humanos. A doutrina nacional especializada em Direito Civil, especificamente em Direito de(as) Família(s), praticamente se mantém completamente alheia às decisões sobre o tema proferidas pelas cortes constitucionais de outros países - ainda que bastante famosas internacionalmente, como o caso Obergefell, pelo qual a Suprema Corte dos Estados Unidos reconheceu o casamento entre pessoas do mesmo sexo como um direito tutelado pela constituição estadunidense. Ter contato profundo com casos paradigmáticos das cortes mais relevantes do mundo - inclusive os tribunais de Direitos Humanos - permite, entre outras coisas, buscar inspiração para futuros desenvolvimentos do direito pátrio, bem como analisar comparativamente com a própria história do direito no Brasil. Isso é particularmente verdade sobre a temática ora trabalhada, considerando o protagonismo assumido pelo Supremo Tribunal Federal e ao Superior Tribunal de Justiça em casos relacionados ao reconhecimento das uniões estáveis e dos casamentos entre pessoas do mesmo sexo. Este artigo pretende suprir esse gap, além de incentivar iniciativas semelhantes em outros temas.

O objetivo geral dessa investigação é demonstrar como a Corte Europeia de Direitos Humanos se debruçou sobre a obrigação atribuída aos países signatários da CEDH no sentido do reconhecimento formal das uniões entre pessoas do mesmo sexo. De forma específica, descreveremos a jurisprudência da Corte anterior ao caso Oliari; observaremos os fatos e o caminho do referido caso até a ECtHR; semelhantemente, destacaremos os principais fundamentos da opinião majoritária da Corte, bem como da opinião concorrente. Ao final, identificaremos na doutrina especializada reflexões e repercussões da mencionada decisão. Este artigo tem uma natureza predominantemente descritiva; apesar de uma necessária investigação crítica mais aprofundada se fazer claramente cabível, isso aqui não é feito por razões de restrição de espaço. Acredita-se que a abordagem majoritariamente descritiva é consistente com o objetivo de pesquisa supramencionado.

Como método, será utilizada principalmente a técnica historiográfica, particularmente baseada na consulta às fontes primárias, quais sejam, os arquivos da ECtHR, 
com a subsequente exposição dos argumentos utilizados no voto vencedor e na opinião concorrente. Também se realizará consulta bibliográfica à doutrina especializada.

\section{BREVE INTRODUÇÃO AO SISTEMA DA EUROPEAN COURT OF HUMAN RIGHTS}

A European Court of Human Rights (ECtHR) funciona como um tribunal internacional apto a interpretar a Convenção Europeia dos Direitos do Homem e das Liberdades Fundamentais (CEDH), de acordo com o artigo 19 da Convenção. Conforme o artigo 34, um requerente pode apresentar uma reclamação contra um Estado, alegando violações à Convenção. Após análise de admissibilidade da reclamação, seus méritos são examinados e é verificado se o Estado signatário de fato violou, e em que medida, um direito previsto na CEDH.

A ECtHR não tem poderes coercitivos; as suas decisões devem ser implementadas pelos Estados-membros. Por essa razão, a legitimidade da Corte depende da medida em que os Estados estão dispostos a cumprir as referidas decisões (FENWICK, 2016, p.01). Quando a ECtHR se utiliza de mecanismos hermenêuticos para ampliar direitos que não estão textualmente expressos na $\mathrm{CEDH}$, comumente surgem críticas e descontentamento das autoridades nacionais europeias. Especialmente na questão de direitos fundamentais para além do texto da CEDH, são comuns as alegações de que a Corte frequentemente ultrapassa os limites da sua competência interpretativa, que originalmente lhe foi conferida pelo consenso dos Estados-membros (DRAGHICI, 2017, p.01). A título ilustrativo, tem sido argumentado criticamente que a CEDH foi pensada para proteger a família contra o Estado, porém a ECtHR tem subvertido o sentido original da Convenção ao se atribuir o poder de definir o que é família, supostamente atuando de forma indevida como guia para os judiciários e legislativos nacionais (PUPPINCK, 2014, p.06).

Para assegurar que os Estados consintam com o conteúdo dos seus julgados, a Corte vem se valendo de alguns métodos, como o reconhecimento da margem de apreciação das legislações nacionais sobre certas matérias, além de uma análise fundamentada no consenso entre as jurisdições europeias (FENWICK, 2016, p.02). Sobre a margem de apreciação, ela significa o espectro dentro do qual um Estado pode interferir com certa liberdade na regulamentação de direitos individuais (MARZANO, 2017, p.256). Ela engloba o poder que o 
Estado tem de decidir se, quando e como regulará determinada matéria. Sobre o consenso europeu, ele pode ser conceituado como uma ferramenta interpretativa para temas complexos de direitos humanos, tomando como base a solução adotada pela maioria dos Estados signatários da CEDH (RAGONE; VOLPE, 2016, p.474). O recurso ao consenso europeu permite que a ECtHR se valha de um critério objetivo - a orientação que está prevalecendo entre as jurisdições signatárias da CEDH - para fundamentar as suas decisões e manter a sua legitimidade, afastando as críticas. A margem de apreciação e o consenso europeu estão interligados, na medida em que, quando este não existe, aquela é mais ampla - e o contrário também é verdadeiro. Desse modo, a ECtHR busca assegurar um standard universal de direitos humanos, ao mesmo tempo em que respeita as diferenças regionais; entretanto, essa abordagem não é livre de críticas, como será visto na seção 07.

\section{OS PRECEDENTES DA EUROPEAN COURT OF HUMAN RIGHTS SOBRE RELACIONAMENTOS ENTRE PESSOAS DO MESMO SEXO}

A Convenção Europeia dos Direitos do Homem e das Liberdades Fundamentais $(\mathrm{CEDH})$ não conceitua família. A ECtHR trouxe essa definição no caso $X, Y$ and $Z v$. the United Kingdom, de 1997. A Corte estabeleceu que a noção de vida familiar, para fins de tutela pela $\mathrm{CEDH}$, não se limita às entidades formadas pelo casamento, podendo abranger outras relações de fato. Segundo a decisão em $X, Y$ and $Z$, diversos fatores podem ser relevantes para verificar se um relacionamento tem natureza de família, incluindo coabitação, duração do relacionamento e demonstração pública do compromisso entre os parceiros.

Observando a história da jurisprudência da ECtHR, é possível identificar um movimento em direção ao reconhecimento de alguma forma de proteção jurídica às relações entre pessoas do mesmo sexo, enquadrando-as na noção de vida familiar. Até o final da década de 1980, não havia no sistema europeu de direitos humanos qualquer tipo de reconhecimento a essas uniões; contudo, em especial a partir do início dos anos 2000, esse tema tem sido objeto de significativas discussões legislativas e judiciais (ROMITO, 2018, p.161). Há dois precedentes da Corte que abriram os caminhos para a decisão em Oliari: Schalk and Kopf v. Austria e Vallianatos and Others v. Greece.

Em Schalk and Kopf v. Austria, de 2010, a ECtHR pela primeira vez afirmou que um casal homossexual, vivendo em um relacionamento estável, poderia ser considerado uma 
família - ainda que de fato, sem previsão legal específica - e protegido enquanto entidade familiar para fins da CEDH. A decisão foi uma mudança significativa na orientação da jurisprudência da Corte, na medida em que, até Schalk and Kopf, essas uniões eram entendidas como incluídas na proteção à vida privada, porém não na proteção à vida familiar. Também se decidiu que o texto da CEDH não exclui o casamento entre duas pessoas do mesmo sexo. Por outro lado, a Corte compreendeu que a Convenção não exigia necessariamente que os Estados-membros permitissem o casamento entre pessoas do mesmo sexo, não havendo um direito ao casamento homossexual.

Em Vallianatos and Others v. Greece, de 2013, a ECtHR determinou que, quando uma nova forma não-casamentária de relacionamento familiar fosse regulamentada legislativamente, ela deveria ser acessível tanto para casais de sexo oposto quanto para casais do mesmo sexo. Do mesmo modo, a Corte reiterou que um casal homossexual vivendo em um relacionamento de fato se encaixava na noção de vida familiar, para fins de proteção da CEDH.

\section{O CAMINHO ATÉ A ECtHR E OS ARGUMENTOS DAS PARTES}

O caso Oliari and others v. Italy originou-se da junção de duas ações distintas, movidas por seis cidadãos italianos contra a República da Itália. Os dois autores da primeira ação - Enrico Oliari e "A" - eram de Trento, e os quatro autores da segunda ação - Gian Mario Felicetti, Riccardo Perelli Cippo, Roberto Zaccheo e Riccardo Zappa - eram de Milão. Todos questionavam o fato de a legislação italiana não permitir que eles se casassem ou entrassem em algum outro tipo de união civil, o que configuraria uma discriminação em razão das suas orientações sexuais (OLIARI, 2015, p.01).

Enrico Oliari e "A" viviam um relacionamento estável quando, em julho de 2008, decidiram se casar e solicitaram ao órgão competente de Trento habilitação para o casamento - que foi negada em 25 de julho daquele mesmo ano (OLIARI, 2015, p.02). Eles questionaram a negativa ante o Tribunal de Trento, argumentando que a legislação italiana não proibia o casamento entre pessoas do mesmo sexo e que, ainda se fosse o caso, tal proibição seria inconstitucional. Em 24 de fevereiro de 2009, o Tribunal de Trento rejeitou o

\footnotetext{
${ }^{1}$ Foi concedido o anonimato ao requerente "A" em decisão do Vice-Presidente da Quarta Seção, de 07 de janeiro de 2013.
} 
pedido, estabelecendo que, como o Direito Civil italiano exigia que os nubentes fossem de sexo oposto, consequentemente o casamento entre pessoas do mesmo sexo não atendia a um dos mais essenciais pressupostos para ser um ato jurídico existente e válido; além disso, não havia um direito fundamental a se casar, e a norma questionada não seria discriminatória na medida em que as restrições não eram direcionadas especificamente aos requerentes, porém tinham efeitos erga omnes; do mesmo modo, as normas da União Europeia atribuíam às jurisdições nacionais a regulação de tais direitos. Os requerentes recorreram à Corte de Apelação de Trento, que por sua vez reiterou a interpretação do juízo de piso, todavia remeteu o caso à Corte Constitucional, em decorrência das alegações de inconstitucionalidade da legislação. A Corte Constitucional italiana, no caso 138, de 15 de abril de 2010, decidiu que duas pessoas do mesmo sexo tinham o direito fundamental de livremente expressar suas personalidades como um casal, obtendo reconhecimento jurídico dos seus respectivos direitos e deveres; entretanto, esse reconhecimento exigia regulamentação legal, o que deveria necessariamente ser feito pelo Parlamento, e não por aquela Corte; do mesmo modo, como demonstrado pelas outras jurisdições europeias, o Legislativo tinha ampla discricionariedade para determinar o tipo de reconhecimento que haveria para os casais do mesmo sexo, e isso poderia ser feito de outros modos, que não pela instituição do casamento (OLIARI, 2015, p.03).

Em março de 2011, Enrico Oliari e "A" peticionaram seu caso na Corte Europeia de Direitos Humanos, com o número 18766/11. Os requerentes se referiram à evolução que vinha se operando no cenário internacional, com o crescente número de países que já haviam legislado sobre algum tipo de reconhecimento para casais homossexuais; nesse contexto, não havia motivo para essas uniões não serem protegidas pela lei italiana. Aduziram ainda que a Corte Constitucional italiana reconhecera que havia um dever do Parlamento de legislar sobre a matéria, de modo a proteger os direitos fundamentais dos casais formados por pessoas do mesmo sexo, e que o Estado italiano não havia apresentado qualquer justificativa para sua omissão em editar qualquer norma a esse respeito. Do mesmo modo, suscitaram que não havia qualquer conexão entre a proteção da família e o reconhecimento jurídico de uniões de casais homossexuais. Argumentaram ainda que a proteção legal à vida e ao status familiar era crucial para a existência, para o bem-estar e para a dignidade das pessoas. Assim, se o Estado italiano não quisesse lhes autorizar o casamento, que pelo menos lhes desse acesso a qualquer instituto solene que protegesse a sua união, de modo a lhes oferecer segurança jurídica 
(OLIARI, 2015, p.25). Eles alegaram que a impossibilidade de entrar em uma união juridicamente reconhecida na Itália, o que lhes impossibilitava de resguardar os seus direitos e deveres enquanto membros de um casal, consistia em uma violação dos artigos $8^{\circ}$ e $12^{\circ}$ da Convenção Europeia dos Direitos do Homem e das Liberdades Fundamentais (CEDH).

\begin{abstract}
ARTIGO $8^{\circ}$. Direito ao respeito pela vida privada e familiar. 1. Qualquer pessoa tem direito ao respeito da sua vida privada e familiar, do seu domicílio e da sua correspondência. 2. Não pode haver ingerência da autoridade pública no exercício deste direito senão quando esta ingerência estiver prevista na lei e constituir uma providência que, numa sociedade democrática, seja necessária para a segurança nacional, para a segurança pública, para o bem - estar económico do país, a defesa da ordem e a prevenção das infracções penais, a protecção da saúde ou da moral, ou a protecção dos direitos e das liberdades de terceiros.
\end{abstract}

ARTIGO 12 ${ }^{\circ}$. Direito ao casamento. A partir da idade núbil, o homem e a mulher têm o direito de se casar e de constituir família, segundo as leis nacionais que regem o exercício deste direito.

Gian Mario Felicetti e Riccardo Zappa iniciaram um relacionamento em 2003 e passaram a morar juntos em 2005. Em fevereiro de 2011, solicitaram habilitação para o casamento, que foi rejeitada em abril daquele mesmo ano. Eles não questionaram judicialmente a negativa, na medida em que consideraram o supramencionado precedente estabelecido pela Corte Constitucional italiana. Semelhantemente, Riccardo Perelli Cippo e Roberto Zaccheo iniciaram um relacionamento em 2002, mesmo ano em que passaram a morar juntos. Em novembro de 2009, solicitaram habilitação para o casamento, que foi rejeitada 02 dias depois. Eles questionaram a negativa no Tribunal de Milão, que por sua vez rejeitou o pedido de acordo com o supramencionado precedente estabelecido pela Corte Constitucional italiana (OLIARI, 2015, p.05). Em junho de 2011, Felicetti, Zappa, Cippo e Zaccheo peticionaram seu caso na Corte Europeia de Direitos Humanos, com o número 36030/11. Os requerentes argumentaram que, à luz da tendência da maioria dos países europeus, a ECtHR deveria impor aos Estados uma obrigação positiva (de fazer), no sentido de assegurar que casais formados por pessoas do mesmo sexo tivessem acesso a algum instituto, qualquer que fosse o nome dado a ele, que fosse mais ou menos equivalente ao casamento. Aduziram que isso era particularmente verdadeiro em relação à Itália, considerando que a Corte Constitucional daquele país reconhecera no caso 138/10 o direito de casais homossexuais terem as suas uniões juridicamente reconhecidas, com atribuição legal dos respectivos direitos e deveres - e que, apesar disso, o legislador italiano permanecera 
inerte (OLIARI, 2015, p.26). Também sustentaram que o governo italiano não demonstrara de que modo o reconhecimento das suas uniões afetaria negativamente as assim chamadas famílias tradicionais; do mesmo modo, o Estado não comprovara que a prevenção de eventuais efeitos adversos, se existentes, não poderia ser alcançada por meios menos restritivos do que a inexistência de qualquer instituto em favor desses casais (OLIARI, 2015, p.27). Os requerentes inferiram que a ECtHR, no papel de guardiã da CEDH e dos seus valores fundamentais, tinha o dever de proteger as minorias. Também argumentaram que, se a ECtHR simplesmente atribuísse às autoridades de cada Estado a decisão sobre a matéria em questão, ela estaria falhando em notar que certas escolhas nacionais poderiam ser feitas na verdade com base em indevidas atitudes discriminatórias contra homossexuais, e não como resultado de um adequado processo democrático (OLIARI, 2015, p.28). Aduziram ainda que a falta do reconhecimento das suas uniões os colocava em desvantagem, em relação a casais heterossexuais, em diversos aspectos - e que a única base para a diferença no tratamento jurídico da questão era a sua orientação sexual - o que configurava uma discriminação direta. Segundo os requerentes, a Itália estava se embasando exclusivamente em sua margem de discricionariedade para justificar o estado de coisas do seu ordenamento jurídico, deixando assim de apresentar quaisquer razões que efetivamente sustentassem o tratamento discriminatório conferido àqueles casais. Eles alegaram que estavam sofrendo discriminação, em violação aos supramencionados artigos $8^{\circ}$ e $12^{\circ}$, em conjunto com o artigo $14^{\circ}$ da CEDH.

\footnotetext{
ARTIGO $1^{\circ}$. Proibição de discriminação. O gozo dos direitos e liberdades reconhecidos na presente Convenção deve ser assegurado sem quaisquer distinções, tais como as fundadas no sexo, raça, cor, língua, religião, opiniões políticas ou outras, a origem nacional ou social, a pertença a uma minoria nacional, a riqueza, o nascimento ou qualquer outra situação.
}

Em resposta aos argumentos suscitados pelos requerentes, o governo italiano observou que não havia na $\mathrm{CEDH}$ um dever imposto aos Estados no sentido de reconhecimento jurídico dos casais do mesmo sexo, na medida em que cada Estado tinha certa margem de discricionariedade para adotar modificações legislativas. Nesse sentido, a questão das uniões homossexuais era sensível culturalmente e socialmente, o que fazia a margem de discricionariedade nacional sobre a matéria ser significativamente ampla em relação ao tempo e ao modo como a respectiva legislação seria adotada. Sendo assim, a 
ECtHR não teria o poder de impor à Itália qualquer obrigação nesse sentido (OLIARI, 2015, p.31).

Em relação ao julgamento do caso 138/10 pela Corte Constitucional, o governo italiano aduziu que a matéria vinha sendo intensamente debatida nos últimos 30 anos, o que demonstrava uma intenção naquele país de se encontrar uma solução que tanto tivesse aprovação pública quanto atendesse às necessidades daquelas minorias. Segundo a Itália, os debates comprovavam que, embora fosse dada atenção à questão por variadas forças políticas, era muito difícil alcançar um equilíbrio entre as diferentes correntes a respeito de um tema social tão delicado (OLIARI, 2015, p.33). O governo italiano também negou categoricamente que o objetivo da inércia legislativa seria a proteção da família dita tradicional ou da moral da sociedade, como tinha sido suscitado pelos requerentes (OLIARI, 2015, p.35).

Houve a intervenção relevante de diversos amici curiae no caso. Em primeiro lugar, foram juntadas informações sobre diversas jurisdições no mundo nas quais havia o reconhecimento - seja por força de lei ou de decisões judiciais - do casamento ou ao menos de uniões jurídicas entre pessoas do mesmo sexo (OLIARI, 2015, p.36-41). ${ }^{2}$ Também foram apresentadas pesquisas de opinião e estatísticas demonstrando por exemplo que, em 2011, mais de $60 \%$ dos italianos adultos entendiam que homossexuais sofriam discriminação, e que quase $75 \%$ dos italianos adultos não viam a homossexualidade como uma ameaça à família (OLIARI, 2015, p.44). Em sentido distinto, também foi apresentada uma petição suscitando receios de que o reconhecimento das uniões entre pessoas do mesmo sexo levasse a futuras discussões sobre outros direitos desses casais, em especial em relação à procriação (OLIARI, 2015, p.46).

\section{A OPINIÃO MAJORITÁRIA}

A Quarta Seção da European Court of Human Rights decidiu o caso Oliari por maioria. A opinião majoritária, ora analisada, foi adotada pelos magistrados Paivi Hiverla, Guido Raimondi, Ledi Bianku e Yonko Grozev. Por outro lado, os juízes Paul Mahoney, Nona Tsotsoria e Faris Vehabovic apresentaram opinião em apartado, redigida pelo primeiro, cujo conteúdo será exposto na próxima seção deste artigo.

\footnotetext{
${ }^{2}$ Consigne-se que foi feita referência expressa à ADIN 4277, julgada pelo Supremo Tribunal Federal; ao RESp 1183378, julgado pelo Superior Tribunal de Justiça; e à Resolução 175 do Conselho Nacional de Justiça.
} 
Primeiramente, em questões de admissibilidade do caso, em atenção à alegação preliminar do governo italiano no sentido de que os requerentes não haviam indicado danos efetivos e concretos que tivessem sofrido, a Corte considerou que havia um interesse pessoal e direto deles - afinal, a Constituição italiana vinha sendo interpretada como excluindo casais do mesmo sexo do âmbito do casamento e também não havia qualquer outra possibilidade de reconhecimento jurídico das uniões dos requerentes (OLIARI, 2015, p.15). Do mesmo modo, o governo suscitara que eles não haviam esgotado as vias judiciais domésticas, em violação ao princípio da subsidiariedade, que permitiria às jurisdições nacionais corrigir as alegadas violações antes que elas chegassem à ECtHR (OLIARI, 2015, p.16). Contudo, a Corte compreendeu que nos princípios do direito internacional havia circunstâncias especiais que afastavam a necessidade de exaustão das vias domésticas; no caso, havia jurisprudência consolidada da Corte Constitucional contra o mérito dos pedidos, o que denotava que os requerentes não tinham qualquer perspectiva de que os seus pedidos seriam atendidos, sendo portanto desnecessário o esgotamento dos recursos judiciais domésticos (OLIARI, 2015, p.19).

Quanto ao mérito, a ECtHR começou analisando a alegação de violação do artigo $8^{\circ}$ da $\mathrm{CEDH}$, supratranscrito. Primeiramente, destacou-se que, embora o referido dispositivo tivesse como objetivo essencial a proteção dos indivíduos contra interferências arbitrárias por parte das autoridades públicas, tal norma também poderia impor a um Estado determinados deveres positivos para assegurar o efetivo respeito aos direitos por ela protegidos; do mesmo modo, esses deveres poderiam envolver a adoção das medidas necessárias para assegurar a vida privada e familiar (OLIARI, 2015, p.48). Nesse sentido, os princípios aplicáveis aos deveres impostos aos Estados - tanto positivos quanto negativos - seriam semelhantes, em especial na atenção dada ao adequado equilíbrio entre os interesses individuais, de um lado, e da comunidade como um todo, de outro lado (OLIARI, 2015, p.49).

A ECtHR consignou que o conceito de respeito a direitos não era claramente definido, notadamente em relação a deveres positivos impostos aos Estados; considerando a diversidade de práticas adotadas em cada jurisdição nacional nos países membros da Convenção, esse conceito (e os requisitos para que o referido respeito fosse suficientemente atendido) poderia variar consideravelmente a depender da matéria da qual se estivesse tratando. Apesar disso, alguns fatores têm sido considerados relevantes na análise do conteúdo desses deveres positivos impostos aos Estados; no caso então discutido, deveria ser 
dado destaque ao impacto sofrido pelos requerentes em razão da discrepância entre o direito positivo e a realidade social (OLIARI, 2015, p.49).

Ressaltou-se que os Estados-membros da Convenção tinham uma certa margem de discricionariedade na implementação das suas obrigações decorrentes do artigo $8^{\circ}$ da CEDH; a extensão da referida margem variaria de acordo com uma série de fatores. No contexto da vida privada, a jurisprudência da ECtHR vinha considerando que haveria um restrito espaço para discricionariedade estatal nos casos em que aspectos particularmente importantes da existência ou da identidade de um indivíduo estivessem em jogo. Por outro lado, quando não houvesse consenso entre os Estados-membros do Conselho da Europa - seja a respeito da importância do interesse em questão, seja sobre os melhores meios de protegê-lo -, a margem de discricionariedade seria mais ampla; esse também seria o caso se o Estado tivesse de encontrar um equilíbrio entre interesses públicos e privados concorrentes (OLIARI, 2015, p.49). Expôs-se que a ECtHR que já tinha se debruçado anteriormente sobre a falta de reconhecimento das uniões entre pessoas do mesmo sexo; foi dado especial destaque ao caso então mais recente, Schalk and Kopf v. Austria, no qual se considerara que ainda não havia consenso estabelecido sobre a questão, o que conferia aos Estados alguma margem de apreciação a respeito do tempo em que mudanças legislativas sobre a matéria seriam realizadas (OLIARI, 2015, p.50).

A Corte reconheceu que, no presente caso, os requerentes tanto não podiam se casar quanto estavam impedidos de entrar em qualquer instituto juridicamente válido - como uniões civis ou parcerias registradas - que fosse capaz de lhes garantir o reconhecimento do seu status e os consequentes direitos relevantes a pessoas em relacionamentos familiares estáveis. Nesse sentido, segundo o ordenamento jurídico italiano, os requerentes apenas poderiam ser considerados membros de uniões de facto, cuja regulamentação pode ser feita por contratos com escopo significativamente limitado, não sendo suficientes em relação a necessidades fundamentais de um casal - inclusive obrigações alimentares e direitos sucessórios. Ademais, esses contratos de uniões de fato estavam à disposição de quaisquer pessoas que coabitassem, independentemente de manterem entre si um compromisso estável; por outro lado, como eles exigiam a coabitação, violavam o entendimento da própria ECtHR de que a existência de uma união estável independia de coabitação (OLIARI, 2015, p.51). Assim, a Corte considerou que, deixando de lado o fato de que tais contratos de união de fato somente passaram a estar à 
disposição dos requerentes em dezembro de 2013, eles não poderiam ser considerados como reconhecimento e proteção adequada às relações dos requerentes (OLIARI, 2015, p.52).

A ECtHR observou ainda que não se tinha demonstrado nem que o Judiciário italiano poderia reconhecer formalmente tais uniões nem quais seriam as consequências de um reconhecimento feito de tal modo. Os tribunais italianos vinham tomando decisões caso a caso sobre a matéria, em um cenário de bastante incerteza e insegurança sobre vários direitos - em especial porque o Estado italiano vinha reiteradamente se opondo aos direitos requeridos nos referidos processos judiciais domésticos. A ECtHR ressaltou que a necessidade dos casais formados por pessoas do mesmo sexo de constantemente ter de recorrer ao Judiciário para obter tratamento igualitário, por si só, já configuraria um significativo empecilho ao direito dos requerentes de respeito por suas vidas privadas e familiares - o que é agravado pelo mencionado estado de incerteza (OLIARI, 2015, p.52).

Destacou-se que existia um conflito entre a realidade social dos requerentes - que viviam seus relacionamentos abertamente na Itália - e a lei - que não lhes conferia reconhecimento oficial. Depreendeu-se que a imposição de um dever de reconhecer e proteger as uniões homossexuais, de forma a fazer o ordenamento jurídico refletir a realidade social, não representaria um ônus significativo para o Estado italiano, seja legislativo, seja administrativo ou de qualquer outra natureza. Além disso, uma legislação nesse sentido serviria a uma necessidade social importante; a jurisprudência da ECtHR já indicava o intrínseco valor das uniões civis, em especial por trazerem a ideia de legitimidade social e jurídica para os casais homossexuais. Por outro lado, notou-se que o governo italiano não demonstrara qualquer interesse social que justificasse a inércia legislativa naquele país (OLIARI, 2015, p.53).

Em relação à margem de apreciação do Estado italiano a respeito de (se, como, quando) legislar sobre a questão, a ECtHR observou que a sua extensão dependia de diversos fatores. Na medida em que o caso ora discutido tratava apenas da necessidade genérica de reconhecimento e proteção dos casais formados por pessoas do mesmo sexo, a Corte considerou que se tratava de aspectos relevantes para a existência e a identidade dos indivíduos - consequentemente, a margem de discricionariedade seria mais estreita. Do mesmo modo, a ECtHR notou que, depois do caso Schalk and Kopf, o movimento em direção ao reconhecimento jurídico dos casais homossexuais tinha continuado a se desenvolver rapidamente tanto na Europa quanto globalmente - o que deveria receber a devida 
importância. A Corte reconheceu que, geralmente, o Estado nacional é mais bem situado para avaliar os interesses de sua população; contudo, no presente caso, a Itália aparentemente não tinha dado a importância devida aos indicativos dados tanto pela população italiana quanto pelas autoridades do Judiciário nacional. Nesse sentido, a ECtHR ressaltou que a Corte Constitucional da Itália admitira a necessidade de reconhecer e proteger as uniões formadas por pessoas do mesmo sexo (OLIARI, 2015, p.54). Da mesma forma, as estatísticas apresentadas indicavam que já havia na população local substancial aceitação aos casais homossexuais, bem como apoio ao seu reconhecimento e proteção. Apesar disso, o Legislativo italiano tinha - talvez voluntariamente, talvez por fracasso - permanecido incapaz de atender às indicações judiciais e populares no sentido de aprovar as normas necessárias sobre a questão. A ECtHR deu especial destaque ao fato de que, ao não cumprir por um longo período de tempo uma obrigação reconhecida pela Corte Constitucional, o Parlamento italiano permanecia violando a Constituição daquele país (OLIARI, 2015, p.55).

$\mathrm{Na}$ ausência de qualquer interesse social relevante suscitado pelo Estado italiano, contra o qual poderiam ser ponderados os interesses dos requerentes, e à luz das conclusões às quais chegou o Judiciário italiano, a maioria da Quarta Seção da European Court of Human Rights decidiu que a Itália ultrapassara os limites da sua margem de discricionariedade a respeito da legislação sobre casais homossexuais, consequentemente violando seus deveres positivos no sentido de assegurar aos requerentes um instituto jurídico específico e adequado para o reconhecimento e a proteção da união entre pessoas do mesmo sexo. Desse modo, concluiu-se que tinha havido uma violação do artigo $8^{\circ}$ da CEDH (OLIARI, 2015, p.56).

Tendo chegado à sua decisão à luz do artigo $8^{\circ}$, a Corte considerou desnecessário analisar se também tinha ocorrido uma violação do artigo $14^{\circ}$. Acerca da alegada violação do artigo $12^{\circ}$, no sentido de que os requerentes estavam sofrendo discriminação em razão da proibição do seu casamento, a ECtHR compreendeu que tal alegação não deveria prosperar. Os requerentes haviam suscitado que desde o julgamento em Schalk and Kopf, muitas jurisdições tinham legislado a favor do casamento entre pessoas do mesmo sexo e que a Corte deveria reanalisar a questão. A ECtHR notou que, no referido precedente, a Corte tinha optado por não se apressar em substituir o julgamento dos países pelo seu próprio compreendendo, assim, que o artigo $12^{\circ}$ não impunha uma obrigação de reconhecimento do casamento homossexual. Em Oliari, a ECtHR reiterou seu entendimento de que o 
mencionado dispositivo não impunha deveres positivos quanto ao casamento entre pessoas do mesmo sexo (OLIARI, 2015, p.57).

$\mathrm{Na}$ medida em que a decisão reconheceu que ocorrera uma violação do artigo $8^{\circ}$ da $\mathrm{CEDH}$, a Corte passou a aplicar o artigo $41^{\circ}$ da Convenção, in verbis.

\begin{abstract}
ARTIGO $41^{\circ}$ Reparação razoável. Se o Tribunal declarar que houve violação da Convenção ou dos seus protocolos e se o direito interno da Alta Parte Contratante não permitir senão imperfeitamente obviar às consequências de tal violação, o Tribunal atribuirá à parte lesada uma reparação razoável, se necessário.
\end{abstract}

Os requerentes do caso 18766/11 argumentaram que tinham sofrido danos materiais como não recebimento de bônus ou licenças familiares, impossibilidade de contratar empréstimos conjuntamente - e imateriais. Os requerentes do caso 36030/11 pediram danos não-pecuniários, em uma quantia a ser determinada pela ECtHR, bem como a recomendação específica ao Estado italiano para legislar em favor de uniões civis para casais homossexuais. A Corte entendeu que os danos patrimoniais alegados não estavam devidamente quantificados nem justificados; entretanto, compreendeu que tinha havido danos extrapatrimoniais, arbitrados em 05 mil euros para cada um dos requerentes, além de custas e tributos eventualmente incidentes. A ECtHR também observou que a ausência de legislação reconhecedora e protetiva violava os direitos dos requerentes; assim, determinou à Itália o dever de implementar medidas apropriadas para atender seu dever de assegurar o respeito à vida privada e familiar dos requerentes e de outras pessoas nas mesmas circunstâncias (OLIARI, 2015, p.58).

\title{
6 A OPINIÃO CONCORRENTE COM O JULGAMENTO
}

Além da opinião majoritária da Quarta Seção da ECtHR, três juízes apresentaram uma opinião concordando com o resultado do julgamento, no sentido de ter havido violação do artigo $8^{\circ}$ da $\mathrm{CEDH}$, porém utilizando fundamentação distinta, mais restrita do que a adotada pela maioria. A opinião minoritária foi redigida pelo Judge Mahoney, tendo a adesão dos Judges Tsotsoria e Vehabovic. Eles entenderam que não havia a necessidade de impor à Itália uma obrigação positiva de legislar especificamente sobre o reconhecimento e a proteção aos casais formados por pessoas do mesmo sexo (OLIARI, 2015, p.61). 
A opinião minoritária considerou que o Estado italiano tinha escolhido, por meio de suas cortes superiores, notadamente sua Corte Constitucional, declarar que duas pessoas do mesmo sexo vivendo uma coabitação estável tinham o direito fundamental, à luz da Constituição italiana, de obter reconhecimento jurídico dos direitos e deveres pertinentes à sua união. Para os três juízes, o artigo $8^{\circ}$ fora violado em razão da (falta de) atuação do Parlamento, que falhara em adequadamente por em prática a mencionada declaração judicial, afetando assim a vida privada e familiar dos requerentes (OLIARI, 2015, p.61).

A minoria ressaltou que, de acordo com o ordenamento constitucional italiano, a Corte Constitucional pode se manifestar sobre a inconstitucionalidade de uma legislação existente, porém não tem os poderes para preencher uma lacuna legislativa como a reconhecida no caso 138/2010 (OLIARI, 2015, p.62). O único remédio que aquele Tribunal tem diante de lacunas legais é solicitar ou requerer ao Parlamento a adoção das necessárias medidas legislativas. Apesar de isso ter sido feito sobre a matéria, já havia mais de 05 anos desde a referida decisão, sem a edição das normas apropriadas. Nesse contexto, os requerentes tinham um direito fundamental reconhecido pelo Judiciário, mas com exercício impossibilitado em razão da inércia do Legislativo - ou seja, estavam em um limbo jurídico, condenados a um estado de insegurança jurídica quanto aos efeitos decorrentes das suas uniões (OLIARI, 2015, p.62).

Para a opinião minoritária, não seria necessário para a ECtHR decidir se a Itália teria ou não um dever positivo de reconhecer juridicamente as uniões homossexuais em seu ordenamento. Isso porque a decisão da Corte Constitucional já configurava uma intervenção estatal positiva na esfera das vidas privadas e familiares dos requerentes, e deveria ser tratada como tal (OLIARI, 2015, p.63). Entretanto, essa intervenção estatal deveria ser tida como insuficiente e incompatível com os requerimentos impostos pelo artigo $8^{\circ}$ da CEDH. Em outras palavras, não é que a Itália tinha um dever positivo de agir a ser reconhecido pela ECtHR, e sim que a sua atuação tinha sido inadequada.

Para a minoria da ECtHR, inquestionavelmente a Itália tinha uma margem de discricionariedade a respeito do status a ser conferido a esses casais e ao timing de edição da legislação pertinente; por outro lado, aquele país tinha violado um dever de boa-fé para com os seus cidadãos, por não ter suficientemente adotado as medidas para preencher a lacuna identificada pela Corte Constitucional (OLIARI, 2015, p.64). Apesar disso, eles discordavam da opinião majoritária por recear que a decisão da maioria acabasse sendo compreendida 
como um dever positivo imposto a todos os Estados-membros da $\mathrm{CEDH}$, e não apenas à Itália, à luz das circunstâncias específicas daquele país (OLIARI, 2015, p.65). Por essa razão, a minoria sustentava que o caso não fosse decidido no sentido de entender que se impunha à Itália um dever positivo, mas que a sua atuação até o momento tinha sido insatisfatória.

\section{REFLEXÕES SOBRE O CASO OLIARI AND OTHERS V. ITALY E ALGUNS DESDOBRAMENTOS}

Na sequência da decisão em Oliari, em alguns meses o Parlamento italiano se desincumbiu da obrigação que lhe tinha sido determinada pela Corte. Em 20 de maio de 2016, foi sancionada a lei 76/2016, que reconhece a união civil entre pessoas do mesmo sexo - e os consequentes direitos e deveres recíprocos entre os parceiros. A lei também é conhecida como Legge Cirinnà, em homenagem à Senadora Monica Cirinnà, autora do projeto original que acabou sendo aprovado pelo Parlamento. A nova legislação continua não autorizando que pessoas do mesmo sexo se casem, todavia atribui às uniões civis um significativo número de direitos que anteriormente decorriam exclusivamente do casamento. Entretanto, ainda há distinções: por exemplo, filhos nascidos durante as uniões civis têm a parentalidade reconhecida apenas do genitor biológico; ademais, esses parceiros estão expressamente proibidos de adotar conjuntamente uma criança.

Andy Hayward (2016, p.01-03) elogia a decisão em Oliari, tanto por reconhecer a importância e o valor da ratificação estatal de relações interpessoais (entre pessoas do mesmo sexo), quanto por coloca pressão nos Estados signatários da CEDH para reconhecer as uniões homossexuais. Por outro lado, ele destaca três limitações da decisão: primeiramente, a Corte perdeu a oportunidade de analisar o artigo $14^{\circ}$, para verificar se se tratava de hipótese de discriminação exercida pelas jurisdições nacionais contra os homossexuais; em segundo lugar, a obrigação positiva imposta à Itália foi vinculada a diversos fatores específicos àquele país (as estatísticas, a decisão da Corte Constitucional), o que pode dificultar o reconhecimento do mesmo dever a outros Estados; por fim, a perda de oportunidade de revisitar a discussão sobre o direito ao casamento entre pessoas do mesmo sexo.

Paul James Johnson e Silvia Falcetta (2018, p.33) igualmente lamentam que a Corte não tenha se debruçado sobre a questão à luz dos argumentos da discriminação sofrida pelos casais formados por pessoas do mesmo sexo. Eles aduzem que, por um lado, a ECtHR 
desenvolve sua jurisprudência sobre diversos aspectos da orientação sexual no que diz respeito à vida privada e familiar; por outro lado, a Corte permanece inflexível em relação aos direitos decorrentes especificamente do casamento dos quais os casais homossexuais continuam sendo excluídos. Os referidos autores sustentam que se trata de um regime de direitos humanos separate but equal - casais de pessoas do mesmo sexo têm um direito a um instituto jurídico que lhes reconheça e proteja, porém esse instituto não necessariamente é o casamento. Johnson e Falcetta acreditam que essa distinção tem de ser erradicada, porém que a Corte tem criado um verdadeiro firewall em torno do casamento, dificultando o acesso a esse instituto.

Ocorre que o reconhecimento das uniões entre pessoas do mesmo sexo é um tema que divide a Europa. Enquanto boa parte dos países da Europa Ocidental tem leis ou jurisprudências progressistas e favoráveis a essas uniões, o mesmo não ocorre de modo geral em países da Europa Central e Oriental. Nesse contexto, a ECtHR se vê no papel de equilibrar, de um lado, a discriminação contra minorias sexuais e, de outro lado, a manutenção da sua autoridade em relação aos Estados que tratam a matéria com hostilidade, conforme o exposto anteriormente na seção 02 deste artigo (FENWICK, 2016, p.03). A ECtHR buscou de toda forma evitar entrar naquilo que poderia ser considerado um ativismo político-judiciário. Por essa razão, a decisão em Oliari foi substancialmente fundamentada em circunstâncias específicas da Itália, como a alta aprovação da população local em relação ao tema, bem como os casos já julgados pelo Judiciário italiano. Por esse mesmo motivo, a Corte não se preocupou em reconhecer expressamente um direito oponível a todos os outros Estados-membros. Especificamente sobre o casamento entre pessoas do mesmo sexo, valendo-se da falta de consenso entre os países europeus, a Corte continua a entender que os Estados-membros têm uma significativa margem de apreciação para decidir sobre a matéria (HAMILTON, 2018, p.02).

Sabrina Ragone e Valentina Volpe (2016, p.475) destacam os dois modos como o consenso europeu foi utilizado em Oliari. Por um lado, 24 dos 47 Estados-membros tinham adotado algum modo de reconhecimento das uniões entre pessoas do mesmo sexo, podia ser identificado um consenso emergente nesse sentido, o que pesou em favor da decisão contra a Itália nesse sentido. Por outro lado, a questão do casamento entre pessoas do mesmo sexo era diferente: ele era legalizado em apenas 11 dos 47 Estados-membros, portanto inexistindo 
consenso nesse sentido, razão pela qual ainda não poderia ser identificado na CEDH um direito ao casamento homossexual.

A ECtHR se vale do método do consenso para manter sua legitimidade, contudo ele pode se mostrar problemático. Conforme aduzido por Masuma Shahid (2017, p.193), atribuir uma ampla margem de decisão aos Estados pode levar a um tratamento discriminatório contra as minorias, na medida em que as jurisdições nacionais nem sempre levam em consideração os interesses dessas minorias no momento de regulamentar matérias com conteúdo moral e ético bastante sensível, como é o caso do casamento entre pessoas do mesmo sexo. Por essa razão, segundo Shahid, a ECtHR deveria assumir um papel mais assertivo na proteção e promoção dos direitos dos homossexuais, em vez de simplesmente recorrer ao método baseado no consenso europeu. Embora reconheça as severas críticas que a ECtHR sofreria caso adotasse uma postura pró-casamento LGBT, Masuma Shahid (2017, p.195) entende que há maiores danos à legitimidade e à credibilidade da Corte enquanto guardiã da CEDH quando ela permite que alguns Estados-membros, utilizando-se da margem de apreciação, continuem dando tratamento discriminatório às minorias sexuais, privando-as de direitos básicos e de proteção jurídica.

Andrew Small (2015, p.01), logo após a decisão, aduziu que, embora os italianos pudessem comemorar o resultado de Oliari, a sensação era de desapontamento - em especial por não se ter entrado no mérito da discriminação sofrida pelos casais homossexuais. Para ele, perdeu-se a oportunidade de estabelecer que casais formados por pessoas do mesmo sexo são substancialmente iguais aos casais formados por pessoas de sexo oposto. O autor também questiona o fato de a decisão ter se embasado na aceitação social de tais uniões na Itália, na medida em que homossexuais continuam tendo direito à vida privada e familiar mesmo naquelas sociedades mais conservadoras. Giuseppe Zago $(2015$, p.03) ressaltou que a Corte deveria ter analisado a questão da discriminação: se casais em situação semelhante são tratados diferentemente em razão das orientações sexuais dos seus integrantes; em caso positivo, se a legislação discriminatória era fundamentada em razões particularmente legítimas, convincentes e adequadas. Brian Soucek (2018, p.1109) destaca que permanece em aberto o quanto específico e limitado o precedente estabelecido em Oliari será; também questiona se a Corte irá aplicar esse entendimento no futuro, em relação a Estados nos quais nem a lei, nem a jurisprudência constitucional, nem a realidade social se mostram a favor dos direitos das minorias sexuais. Soucek (2018, p.1118) igualmente lamenta que a ECtHR não 
tenha focado sua análise à luz de questões de igualdade. Vito John Marzano (2017, p.250) vê a questão com pessimismo, entendendo que Oliari terá pouca influência no desenvolvimento do direito em Estados mais conservadores, notadamente porque se embasou em circunstâncias muito específicas da situação italiana. Frances Hamilton (2018, p.04) menciona especificamente a Rússia, na qual a homofobia ainda é forte na sociedade: como a ECtHR decidiria a questão?

A evolução da jurisprudência da Corte pós-Oliari, por um lado, tem reafirmado o direito de casais homossexuais de serem reconhecidos como famílias; todavia, ainda há certa relutância em afirmar que eles têm um direito, oponível aos Estados, ao casamento. Em 2016, a ECtHR decidiu em Chapin and Charpentier v. France que os artigos $8^{\circ}$ e $12^{\circ}$ da CEDH não incluem o direito ao casamento entre pessoas do mesmo sexo. Em 2017, em Orlandi and Others v. Italy, a Corte reiterou a decisão tomada em Oliari, estabelecendo que casais homossexuais devem ser juridicamente reconhecidos como uma família. Em 2021, em Fedotova and Others $v$. Russia, a ECtHR por unanimidade decidiu que a recusa peremptória a qualquer modo de formalizar a união entre parceiros do mesmo sexo consistia em uma violação do artigo $8^{\circ}$ da CEDH. Em Fedotova, a Corte compreendeu que a Rússia tem a obrigação de assegurar o respeito pela vida privada e familiar dos requerentes (casais homossexuais), devendo assim estabelecer um instituto jurídico que reconheça e proteja os seus relacionamentos. A Corte verificou que a falta de reconhecimento jurídico daquelas uniões gera um conflito entre a realidade social e os seus efeitos legais. A ECtHR rejeitou os argumentos suscitados pela Rússia no sentido de que a sociedade tinha um interesse legítimo na impossibilidade de formalização daqueles relacionamentos. A Corte concluiu que, negando o acesso a qualquer reconhecimento formal dos casais do mesmo sexo, as autoridades russas extrapolaram sua margem de discricionariedade sobre a matéria. A ECtHR decidiu em Fedotova que a Rússia era obrigada a reconhecer tais uniões, porém mantinha a sua discricionariedade de como seria a forma mais apropriada de fazê-lo e de regulamentá-las; em outras palavras, o Estado russo permanecia não sendo obrigado a autorizar o casamento homossexual.

\section{CONCLUSÃO}


Neste artigo, observou-se que a European Court of Human Rights (ECtHR) funciona como um tribunal internacional apto a interpretar a Convenção Europeia dos Direitos do Homem e das Liberdades Fundamentais (CEDH), assegurando que a Convenção seja respeitada pelos Estados signatários. Verificou-se que a Corte não tem poderes coercitivos, o que faz com que a sua legitimidade dependa do consentimento de os Estados cumprirem as suas decisões. Notou-se que, por essa razão, a Corte vem utilizando mecanismos hermenêuticos que mantenham a sua legitimidade, como o consenso europeu e a margem de decisão atribuída aos Estados-membros.

Verificou-se que a Corte Constitucional italiana já havia decidido que casais formados por pessoas do mesmo sexo não tinham um direito constitucional ao casamento, porém tinham o direito fundamental do reconhecimento das suas uniões como entidades familiares pela legislação civil. Percebeu-se que, apesar disso, o Parlamento italiano permaneceu inerte, não editando qualquer norma que permitisse aos casais homossexuais a obtenção de um reconhecimento formal enquanto famílias - o que lhes privava dos direitos e deveres decorrentes desse status. Por essa razão, três casais recorreram à ECtHR.

Observou-se que a maioria da Quarta Seção da ECtHR considerou que a Itália tinha atentado contra o direito à vida privada e familiar dos requerentes, em violação ao artigo $8^{\circ}$ da CEDH. Para a Corte, a inexistência de um instituto jurídico no ordenamento italiano que reconhecesse casais formados por pessoas do mesmo sexo enquanto entidades familiares trazia uma série de consequências negativas para essas pessoas. Isso era particularmente problemático no contexto italiano, considerando a inércia do Parlamento em editar as regulamentações relevantes mesmo após o reconhecimento, pelo mais alto tribunal daquele país, de que seria necessário legislar a esse respeito. Isso também contrastava com o elevado índice de aceitação social das uniões homossexuais pela população italiana em geral. Essa omissão evidente extrapolava os limites da margem de discricionariedade atribuída às autoridades italianas para decidir sobre a regulamentação da matéria; essa margem seria mais estreita nesse caso diante da importância do tema para a existência dos indivíduos, bem como pelas já mencionadas decisões do Judiciário e pelo movimento das jurisdições europeias no sentido de haver certo consenso sobre o reconhecimento jurídico de tais uniões. Por esses motivos, a ECtHR decidiu que havia um dever positivo, uma obrigação de agir, atribuído à Itália, consistente em editar a legislação necessária para reconhecer enquanto entidades familiares os casais formados por pessoas do mesmo sexo. 
Identificou-se que a Itália rapidamente desincumbiu-se do referido dever imposto pela ECtHR, editando em poucos meses a legislação necessária para reconhecer e atribuir direitos e deveres às uniões entre pessoas do mesmo sexo. Entretanto, também se percebeu que a lei civil italiana permanece rejeitando o acesso desses casais ao instituto do casamento, além de não lhes atribuir alguns dos direitos decorrentes do casamento.

Observou-se que a jurisprudência da ECtHR pós-Oliari continuou no sentido de negar a existência na $\mathrm{CEDH}$ de um direito ao casamento entre pessoas do mesmo sexo, oponível aos Estados signatários, à luz da ausência de consenso sobre o tema entre as jurisdições europeias. Por outro lado, também se identificou que a Corte continua admitindo a existência de um direito ao reconhecimento das uniões homossexuais como entidades familiares, ainda que em contextos diferentes daquele em que Oliari foi decidido. Nesse sentido, na recente decisão do caso Fedotova, a Corte compreendeu que a Rússia também violara a CEDH ao não dar qualquer tipo de proteção jurídica a essas uniões.

\section{REFERÊNCIAS}

DRAGHICI, C. The Strasbourg Court between European and local consensus: antidemocratic or guardian of democratic process? Public Law, 2017.

FEDOTOVA and others v. Russia, nos. 40792/10, 30538/14 and 43439/14, 13 July 2021.

FENWICK, H. Same sex unions at the Strasbourg Court in a divided Europe: driving forward reform or protecting the Court's authority via consensus analysis? European human rights review, n. 03, 2016.

HAMILTON, Frances. Same-sex marriage, consensus, certainty and the European court of human Rights. European Human Rights Law Review, 2018.

HART, Linda. Anthropology of kinship meets human rights rationality: limits of marriage and family life in the European Court of Human Rights. European societies, vol. 20, n. 05, 2018.

HAYWARD, A. Same-sex registered partnerships - a right to be recognised? Cambridge Law Journal, vol. 75, n. 01, 2016.

JOHNSON, Paul James; FALCETTA, Silvia. Sexual orientation discrimination and article 3 of the European Convention on Human Rights: developing the protection of sexual minorities. European Law Review, 2018. 
MARINAI, Simone. Recognition in Italy of Same-sex marriages celebrated abroad: the importance of a bottom-up approach. European Journal of Legal Studies, vol. 09, n. 01, 2016.

MARZANO, Vito John. Oliari and the European Court of Human Rights: where the Court failed. Pace International Law Review, vol. 29, n. 01, 2017.

MOL, Charlotte. Non-traditional Family Forms \& the International Dimension of Family Life. F\&R, 2016.

OLIARI and others v. Italy, nos. 18766/11 and 36030/11, 21 July 2015.

RAGONE, Sabrina; VOLPE, Valentina. An emerging right to a gay family life? The case Oliari v. Italy in a comparative perspective. German Law Journal, vol. 17, n. 03, 2016.

ROMITO, Angela Maria. The rights of same sex couples under European and Italian Law. Bulletin of the Transilvania University of Brasov, vol. 02, 2018.

SHAHID, Masuma. The right to same-sex marriage: assessing the European Court of Human Rights' consensus-based analysis in recent judgments concerning equal marriage rights. ELR, n. 03, 2017.

SICCARDI, Cecilia. Same-sex couples rights: the role of supranational and national courts in order to fill legal vacuum in the Italian legal framework. La creación judicial del derecho y el diálogo entre jueces. Universitat Autonoma de Barcelona: Belaterra, 2017.

SMALL, Andrew. Oliari v. Italy: a missed opportunity for equality in Strasbourg. London School of Economics Blog. 2015. Disponível em http://blogs.lse.ac.uk/humanrights/2015/07/31/oliarivitalyamissedopportunityforequalityinstrasbourg/. Acesso em 13 de setembro de 2021.

SOUCEK, Brian. Marriage, morality, and federalism: the USA and Europe compared. ICON, vol. 15 , n. 04, 2017.

TRYFONIDOU, A. The ECJ recognises the right of same-sex spouses to move freely between EU Member States: the Coman ruling. European Law Review, vol. 44, n. 05, 2019.

WINKLER, Matteo M. Same-sex marriage, Italian style. Cardozo Journal of Law and Gender, vol. 23, n. 01, 2016.

ZAGO, Giuseppe. Oliari and Others v. Italy: a stepping stone towards full legal recognition of same-sex relationships in Europe. Strasbourg Observers, 16 de setembro de 2015.

Disponível em http://strasbourgobservers.com/2015/09/16/oliariandothersvitalyasteppingstonetowardsfulllegalrecognitionofsamesexrelationshipsineurope/. Acesso em 13 de setembro de 2021. 